\title{
Article \\ Peak Energy Reduction in Flow Shop including Switch-Off Policies and Battery Storage
}

\author{
Paolo Renna *(D) and Sergio Materi (D) \\ School of Engineering, University of Basilicata, 85100 Potenza, Italy; sergio.materi@unibas.it \\ * Correspondence: paolo.renna@unibas.it
}

\begin{abstract}
The energy storage system is typically used in manufacturing systems with renewables to reduce the impact of the instabilities of these sources. The switch-off policies are proposed in the literature to reduce the energy used by the machines in the idle state. This study uses simulation models to investigate the potential application of the energy storage system with switch-off policies to reduce the energy costs related to the use over the peak power constraint. The manufacturing system analyzed is a flow line with the possibility of introducing two switch-off policies considering the two parameters of the battery (capacity and charge rate) and three levels of power fluctuations needed by the manufacturing operations. The results highlight that the charge rate and the power fluctuations of the manufacturing operations are the more important factors that impact the model studied. The switch-off policies have a positive impact and can reduce the energy use over the peak power constraint even at a slower charge rate, which means battery at a lower cost.
\end{abstract}

Keywords: peak energy; flow line; switch-off; battery; simulation

check for updates

Citation: Renna, P.; Materi, S. Peak Energy Reduction in Flow Shop including Switch-Off Policies and Battery Storage. Appl. Sci. 2022, 12, 2448. https://doi.org/10.3390/ app12052448

Academic Editor: Giuseppe Marannano

Received: 28 January 2022

Accepted: 24 February 2022

Published: 26 February 2022

Publisher's Note: MDPI stays neutral with regard to jurisdictional claims in published maps and institutional affiliations.

Copyright: (C) 2022 by the authors. Licensee MDPI, Basel, Switzerland. This article is an open access article distributed under the terms and conditions of the Creative Commons Attribution (CC BY) license (https:// creativecommons.org/licenses/by/ $4.0 /)$.

\section{Introduction and Motivations}

The efficient use of energy is crucial at different levels; the reduction of energy consumption allows to cut the production costs (energy bill) and meet the objective of $\mathrm{CO}_{2}$ emission level. The sector of industrial activities accounts for about $24 \%$ of the global greenhouse gas emissions [1]. A drastic reduction in emissions, around $80 \%$, can be achieved by improving energy efficiency and introducing renewable energy sources [2]. From the point of view of production costs, the energy bill can be reduced by pursuing energy-saving and reducing the peak power costs. In several manufacturing systems, the idling power consumption is comparable to the operating power consumption. Then, the switch-off policies to turn off the idle machines are suitable for many manufacturing processes [3].

The power usage agreement between users and energy providers defines a maximum power constraint. This constraint is necessary to ensure the stability of the power grid and the use over the constraint leads to significant penalty costs [4,5].

The reduction in the price of lithium-ion batteries has made this component available to support the energy storage system [6]. Furthermore, the reuse of Li-ion battery packs for electric vehicles can be very relevant to storage systems in production systems $[7,8]$. Energy storage in manufacturing systems can contribute to saving energy costs. The energy can be stored when the demand is under the maximum power usage constraint and using it when the demand is over the constraint.

The above discussion introduces three topics (battery, switch-off, and peak power constraint) that have been studied separately in the literature.

The literature review (as discussed in the next section) highlights that the energy storage system is used mainly to align the energy provided by renewable sources with the energy demand of the manufacturing system; moreover, the switch-off policies are proposed only to reduce the energy consumed in the idle state of the machines. Then, this study evaluates the introduction of the energy storage system to reduce the costs due to the 
peak power constraint. The other original contribution regards how the switch-off policies and energy storage systems work together and if they can be a real value added to reduce the costs of peak power constraints.

This study proposes and evaluates the introduction of an energy storage system in a flow line that works with switch-off policies. The study considers different battery characteristics as capacity and charging speed. In addition, the power fluctuation is considered in the flow line.

We use the simulation to evaluate the performance compared to a system without an energy storage system. It is evaluated the improvements of the only energy storage system and then the value added by the switch-off policies. To our knowledge, no previous studies investigated the integration of switch policies with the battery storage system.

This paper is organized as follows. Section 2 discusses the recent works proposed in the literature about the energy storage systems, switch-off policies and peak power constraints. Section 3 describes the reference context and the proposed approach with energy storage and switch-off.

Section 4 shows the simulation experiments, while Section 5 discusses the numerical results. Finally, Section 6 reports the conclusions and future research developments.

\section{Literature Review}

In recent years, in literature, there is a lack of studies about the energy efficiency in manufacturing systems using switch-off policies and battery energy storage. For an extensive review, Renna and Materi [9] proposed a survey on the energy efficiency approaches in manufacturing systems. The development of lithium-ion batteries reduces the recharge time and the costs; these batteries allow the introduction of economical storage systems. The battery storage system in manufacturing systems is mainly considered to improve the use of renewable energy that is characterized by fluctuations [10,11]. Materi et al. [12] studied the use of an accumulation system to improve the use of a photovoltaic plant in the context of cutting operations. A model is proposed to adapt the power of the machine by varying the cutting speed to the power supplied by the photovoltaic system. The energy storage system allows increasing the use of renewable energy reducing the $\mathrm{CO}_{2}$ emission.

The costs due to the peak power are studied using the buffer [13] or developing scheduling approaches [14-16]. Sun et al. [17] proposed the shutdown of the machine during the peak power period. Frigerio and Matta [18] proposed a switch-off policy for a single machine based on the time threshold to reduce the number of warm-ups during the switch-on of the machines. The policy works shutting down the machine an interval since the last departure. The authors extend this work in [19] including more parameters.

Su et al. [20] studied the introduction of switch-off policies in the production line to reduce energy consumption. Three policies have been proposed considering the information of the buffers upstream, downstream, and simultaneously upstream and downstream. These policies make it possible to reduce the energy consumed by machines in a state of inactivity. Bernoulli serial production line with the switch-off policies based on the buffers was proposed by Jia et al. [21,22]. Fei et al. [23] proposed a fuzzy controller with Petri net to control the switch off/on of the machines reducing the throughput loss. Expert systems based on fuzzy rules were proposed to obtain a better tradeoff between the production rate and the energy-saving target [24-27]. Marzano et al. [28] proposed an online algorithm consisting of a learning phase to estimate a set of parameters and an optimization phase to find the optimal parameters of the switch-off policy. Renna [29] proposed a dynamic switch-off policy in a pull-controlled production line that uses the downstream buffer level and customer satisfaction. The buffer utilization and the evaluation of other stochastic factors are considered to support the decision on the shutdown machines [30]. Renna and Materi [31] proposed switch-off policies in the job-shop system using the information of direct and indirect workload. 
A study considered the switch-off policy, and the energy storage system was proposed in Schulze et al. [32]. In this work, the characteristics of the battery were not studied, and the switch-off policy is simplified compared to the policies proposed in the literature.

From the analysis of the literature, several works have studied the energy storage system to improve the use of variable renewable energy and in recent years have focused on the introduction of the switch-off to reduce energy consumption in production systems. Few studies consider the impact of battery characteristics to reduce energy beyond the peak power constraint in production systems and, to the authors' knowledge, no study has analyzed the integration of energy storage systems with the shutdown.

Therefore, this paper studies the impact of the battery characteristics to reduce the influence of energy use over the peak power constraint by first asking:

RQ1: What is the impact of the energy storage system characteristics to reduce the energy use over the peak power constraint?

The second research question regards the integration of the energy storage system with the main switch-off policies proposed in the literature, asking:

RQ2: Can the switch-off policies significantly improve the use of the energy storage system to reduce the energy use over the peak power constraint?

Simulation models are developed to answer our two research questions. By considering different battery characteristics (capacity and charge rate), two switch-off policies and three levels of power fluctuations of the manufacturing operations provide information to support decisions in energy-saving costs. The following sections outline the reference context, the simulation model, and the numerical experiments conducted.

\section{Reference Context and Proposed Approach}

The manufacturing system considered is a production line composed of a series of $m$ machines connected in series and separated by buffers. The raw materials are always available, and the buffer of each machine has no capacity limit. The raw items enter following an exponential distribution and each machine has a stochastic power to perform the operation $i(\mathrm{Pi})$. The states of the machine considered are the following [33]: working state, when the machine performs the manufacturing operation; idle state, when the machine is on and can work, but no item is available; off state, the machine is turned off and it is not able to work.

The production system has a constraint due to the energy consumption contract; when the power used is exceeded, the restriction is considered a penalty.

To reduce the cost of the penalty, an energy storage system supported by a battery is introduced. The battery is characterized by the following parameters: the capacity $\mathrm{Cb}$ and the charge factor of the speed $S b$. The degradation of the battery and the decrease in capacity has not been considered.

When the power of the manufacturing system is under the peak constraint, the battery is charged until the capacity is available; otherwise, one machine at once can use the power of the battery to reduce or to bring to zero the power needed over the peak power constraint.

The power to keep the machines idle and off states are always provided by the electricity grid; this is to avoid the problem of not supplying the basic systems of the machines and to ensure the readiness of the machines. Therefore, the battery is used only to support the working state power of the machines.

Each machine has a controller to use the battery energy storage system in particular conditions; when a part should be loaded into the machine, the activities shown in Figure 1 are performed.

When a part enters the machine, the total power of the production system (Ptot) is calculated, adding the necessary power of the task $(P i)$. Each task is characterized by a processing time $(P T i)$ in minutes. 


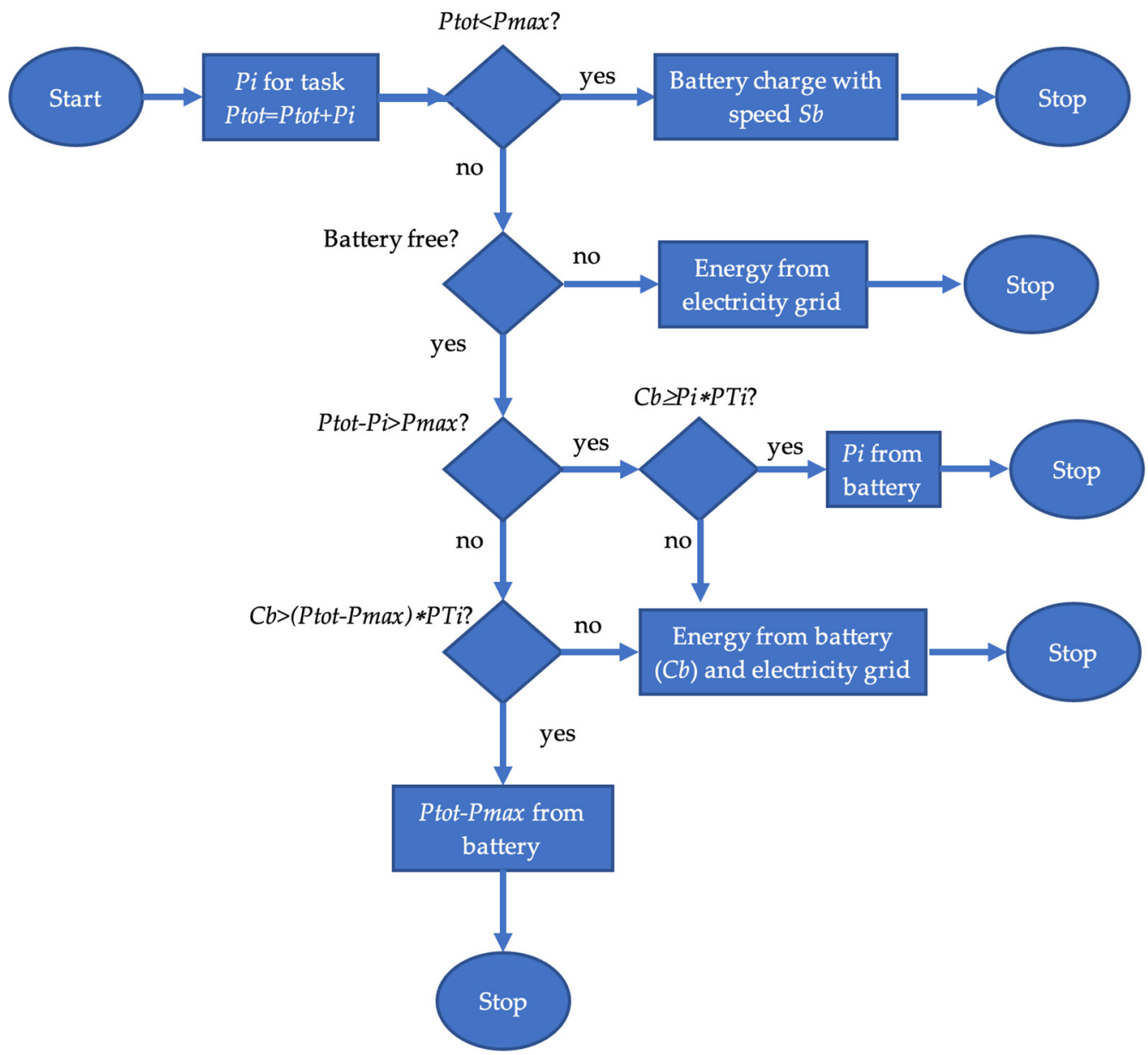

Figure 1. Machine controller activities on enter item.

If the Ptot is lower than the power constraint (Pmax), it is possible to charge the battery. The charge rate is computed as shown in Expression 1:

$$
S b=\left[1.1-\frac{\text { Pmax }- \text { Ptot }}{\text { Pmax }}\right] * K
$$

Expression 1 means that the charging speed depends on the difference between the Pmax of the electricity grid and the Ptot used by the manufacturing system that is the power available to charge the battery. The value 1.1 leads to a minimum value of 0.1 (when the power of the manufacturing system is theoretically null) of the factor $K$ that denotes the performance of the battery in terms of potential charging speed. The factor $K$ is related to the processing time $P T i$, every $S b$ unit time (minute) a $k W * P T i$ is charged.

If the Ptot is greater than the power constraint (Pmax), the controller verifies that the battery is free or that any machine is using the battery. If the battery is used by another machine, the controller switches the entire power $\mathrm{Pi}$ on the electricity grid; otherwise, the controller verifies if the $P i$ is completely over the Pmax, then if the battery has enough capacity, the entire $P i$ is allocated on the battery. If the battery does not have enough capacity, it uses the entire capacity of the battery, and the residual power is allocated on the electricity grid.

Finally, if the $P i$ is not all completely over the Pmax constraint, the controller verifies that the only power over the constraint can be supported by the battery, while the power under the constraint is supplied by the electricity grid. If the battery is not sufficiently charged to supply the power over the constraint, all the battery capacity is used and the 
residual power is allocated on the electricity grid. The tasks performed by the machine controller when an item entered into the system have been represented in Figure 1.

When a part leaves the machine, the machine controller updates the Ptot reducing the value $P i$, and verifies if the Ptot is lower than the Pmax to start the battery charger with the speed $S b$ computed as in the Expression 1.

To improve the efficiency of the energy storage system, the introduction of switch-off policies is considered. In the literature, there are three main switch-off policies proposed: the Upstream, Downstream, and Upstream and Downstream policies [34].

The Upstream policy works on the upstream buffer; when the buffer tends to empty, the machine switches off. The machine switches on when the upstream buffer exceeds a defined level. This policy needs two parameters to set: the low and high levels of the buffer to switch off and on the machine.

The Downstream policy works on the downstream buffer. The machine switches off when the downstream buffer reaches a defined level, and it switches on when the level is under a low level; moreover, this policy needs to set two parameters. In this paper, the Downstream policy is not considered, because this policy does not take into account the final machine of the flow line reducing significantly the potential reduction of power used.

The Upstream and Downstream policy combines the upstream and downstream policies and needs to set four parameters.

\section{Simulation Experiments}

The production line consists of three machines (or three manufacturing stages), and each machine has an upper stream buffer with no capacity limitation. The simulation environment has been developed using the package for Discrete Event Simulation from SIMUL8 Corporation. Figure 2 describes the architecture of the simulation environment developed. The simulation model consists of the following areas:

- The flow line with machines and buffers that emulates the physical manufacturing system;

- $\quad$ each machine has a controller that performs the activities described in the previous section;

- $\quad$ the electricity grid where the information of the controllers defines the electricity load;

- the energy storage system that is charged by the electricity grid and support the machines based on the decisions of the controllers;

- the integration of the electricity grid and the energy storage system to provide the energy to the machines.

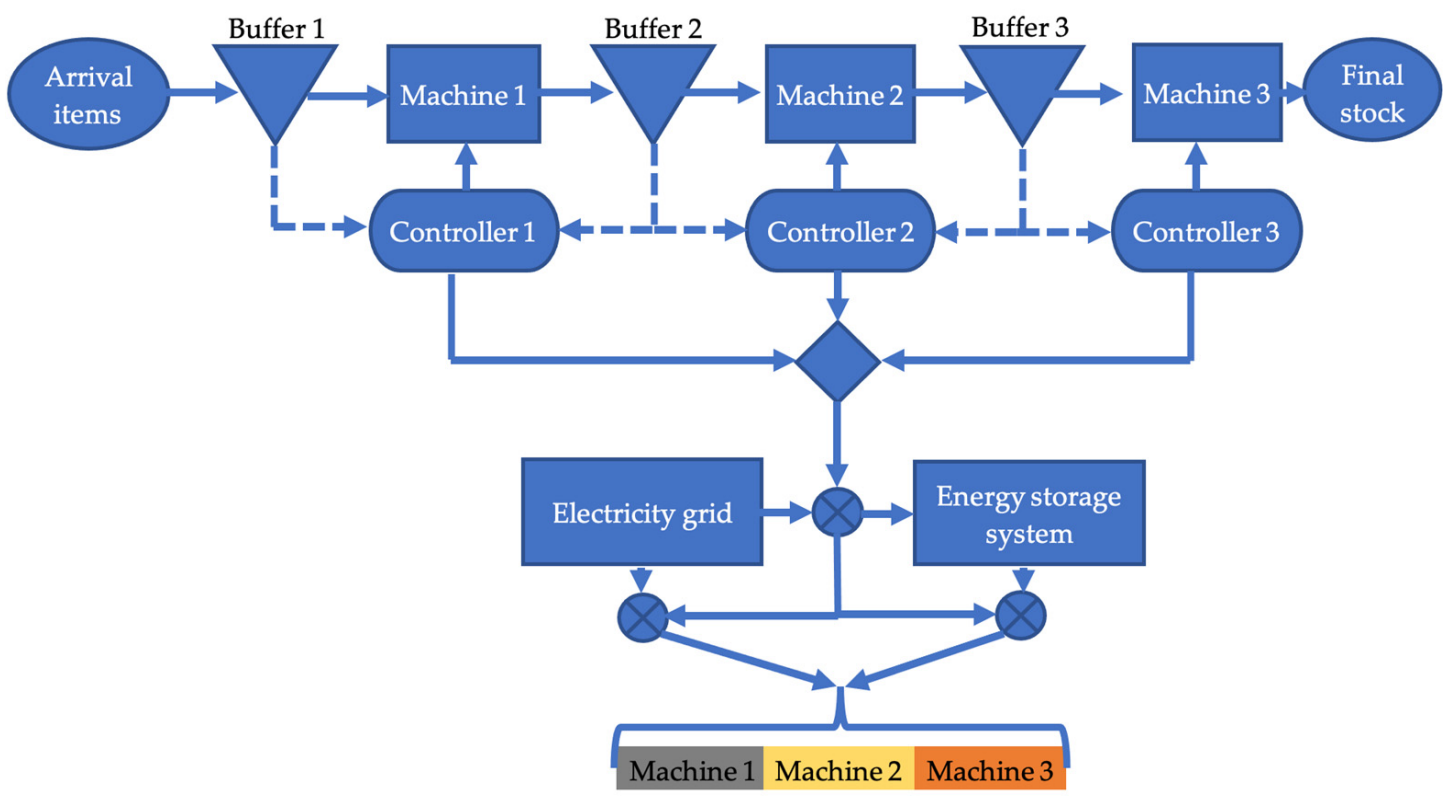

Figure 2. Simulation architecture. 
When a part enters in a machine is determined the power necessary to perform the task is defined and it follows a uniform distribution with a mean of $20 \mathrm{~kW}$ and a percentage of variation $v i$ (Expression 2):

$$
\mathrm{Pi}=U N \operatorname{UFORM}[\mathrm{Pi}-\mathrm{vi} * \mathrm{Pi} ; \mathrm{Pi}+\mathrm{vi} * \mathrm{Pi}]
$$

The constraint Pmax is set equal to the sum of the mean power for the three machines, i.e., $60 \mathrm{~kW}$.

Table 1 reports the experimental classes for the parameters investigated: battery capacity $(\mathrm{Cb})$, charging speed factor $\mathrm{K}$ (see Expression 1), and the power variability (vi) of the tasks. Three levels of battery capacity $\left(10,15,20 \mathrm{~kW} * \mathrm{PT}_{\mathrm{i}}\right)$, charge rate factor $(10,5,2.5)$, and power variability $(10 \%, 20 \%, 30 \%)$ have been considered. The battery capacity is related to the processing time, and $P T_{i}$ follows a normal distribution with mean $10 \mathrm{~min}$ (PTi) and $25 \%$ of standard deviation. The inter-arrival time of the items follows an exponential distribution with a parameter equal to 11 to obtain an average utilization of the machines of $90 \%$.

Table 1. Experimental classes.

\begin{tabular}{|c|c|c|c|}
\hline Exp. No. & $\begin{array}{l}\text { Battery Capacity } \\
\qquad b \text { b }\end{array}$ & $\begin{array}{c}\text { Charge Rate Factor } \\
K\end{array}$ & $\begin{array}{c}\text { Power Variability } \\
\qquad i\end{array}$ \\
\hline 1 & 10 & 10 & 10 \\
\hline 2 & 15 & 10 & 10 \\
\hline 3 & 20 & 10 & 10 \\
\hline 4 & 10 & 5 & 10 \\
\hline 5 & 15 & 5 & 10 \\
\hline 6 & 20 & 5 & 10 \\
\hline 7 & 10 & 2.5 & 10 \\
\hline 8 & 15 & 2.5 & 10 \\
\hline 9 & 20 & 2.5 & 10 \\
\hline 10 & 10 & 10 & 20 \\
\hline 11 & 15 & 10 & 20 \\
\hline 12 & 20 & 10 & 20 \\
\hline 13 & 10 & 5 & 20 \\
\hline 14 & 15 & 5 & 20 \\
\hline 15 & 20 & 5 & 20 \\
\hline 16 & 10 & 2.5 & 20 \\
\hline 17 & 15 & 2.5 & 20 \\
\hline 18 & 20 & 2.5 & 20 \\
\hline 19 & 10 & 10 & 30 \\
\hline 20 & 15 & 10 & 30 \\
\hline 21 & 20 & 10 & 30 \\
\hline 22 & 10 & 5 & 30 \\
\hline 23 & 15 & 5 & 30 \\
\hline 24 & 20 & 5 & 30 \\
\hline 25 & 10 & 2.5 & 30 \\
\hline 26 & 15 & 2.5 & 30 \\
\hline 27 & 20 & 2.5 & 30 \\
\hline
\end{tabular}


The experimental classes are simulated for three different model typologies:

- machines always on;

- machines with upstream policy;

- machines with the upstream and downstream policy.

Each model is simulated with and without an energy storage system. Therefore, the total simulations are 27 (i.e., number of the experimental classes) $\times 3$ (i.e., number of model typologies) +3 (i.e., number of models without energy storage system) $\times 3$ (i.e., number of the different power variability), with a total of 90 simulation classes.

The results are reported for the parameters of the switch-off policies that leads to the same throughput of the models without the switch-off. The parameters are the following:

- Upstream policy considers one item to switch off and 3 items to switch on in the upstream buffer;

- Upstream and downstream policy considers the same parameters of the upstream policy and one item to switch on and 3 items to switch off in the downstream buffer. The performance measures considered are the following:

- Throughput of the manufacturing system; this performance is monitored to obtain the same throughput level of the models studied;

- $\quad$ The energy used over the peak power constraint (energy peak); this performance allows to evaluate the penalty costs;

- $\quad$ The peak power as the maximum value of the electricity grid load;

- Average electricity grid utilization to evaluate the uniformity of the load on the electricity grid;

- The average battery utilization and the percentage capacity use of the battery.

The simulation length is set to $28,800 \mathrm{~min}$ to define a statistical analysis for the terminating simulation approach. For each class, a number of replications able to assure a $5 \%$ confidence interval and $95 \%$ of confidence level for each performance measure has been conducted. The number of replications required varies between 2000 and 3000 .

\section{Numerical Analysis}

The first analysis of the results is conducted using the Analysis of Variance (ANOVA) to know the source of variation of the simulation experiments. The main effects of the battery capacity, charging speed, power fluctuation, and switch-off policy are presented in Table 2.

Table 2. ANOVA analysis.

\begin{tabular}{|c|c|c|c|c|c|}
\hline Source of Variance & Sum of Square & Degree of Freedom & Mean of Square & F-Ratio & $p$-Value \\
\hline \multicolumn{6}{|c|}{ Energy Peak } \\
\hline Battery Capacity & $62,729,371$ & 2 & $31,364,685$ & 1.28 & 0.285 \\
\hline charge rate & $4,203,607,727$ & 2 & $2,101,803,863$ & 85.48 & 0.000 \\
\hline Power fluctuations & $7,152,612,496$ & 2 & $3,576,306,248$ & 145.45 & 0.000 \\
\hline Models & $207,676,538$ & 2 & $103,838,269$ & 4.22 & 0.018 \\
\hline Error & $1,770,323,905$ & 72 & $24,587,832$ & & \\
\hline \multicolumn{6}{|c|}{ Peak Power } \\
\hline Battery Capacity & 8.37 & 2 & 4.18 & 6.63 & 0.002 \\
\hline charge rate & 130.52 & 2 & 65.26 & 103.48 & 0.000 \\
\hline Power fluctuations & 2430.02 & 2 & 1215.01 & 1926.46 & 0.000 \\
\hline Models & 3.85 & 2 & 1.93 & 3.06 & 0.053 \\
\hline Error & 45.41 & 72 & 0.63 & & \\
\hline \multicolumn{6}{|c|}{ Average electricity grid utilization } \\
\hline Battery Capacity & 0.1549 & 2 & 0.07743 & 1.60 & 0.209 \\
\hline charge rate & 8.6491 & 2 & 4.32456 & 89.24 & 0.000 \\
\hline Power fluctuations & 6.4681 & 2 & 3.23404 & 66.74 & 0.000 \\
\hline Models & 0.3074 & 2 & 0.15371 & 3.17 & 0.048 \\
\hline Error & 3.4890 & 72 & 0.04846 & & \\
\hline
\end{tabular}


Table 2. Cont.

\begin{tabular}{|c|c|c|c|c|c|}
\hline Source of Variance & Sum of Square & Degree of Freedom & Mean of Square & F-Ratio & $p$-Value \\
\hline \multicolumn{6}{|c|}{ Average battery utilization } \\
\hline Battery Capacity & 370.50 & 2 & 185.250 & 64.53 & 0.000 \\
\hline charge rate & 783.19 & 2 & 391.594 & 136.42 & 0.000 \\
\hline Power fluctuations & 464.77 & 2 & 232.384 & 80.95 & 0.000 \\
\hline Models & 1.42 & 2 & 0.708 & 0.25 & 0.782 \\
\hline Error & 206.68 & 72 & 2.871 & & \\
\hline \multicolumn{6}{|c|}{ Capacity battery percentage utilization } \\
\hline Battery Capacity & 0.00383 & 2 & 0.00192 & 0.55 & 0.581 \\
\hline charge rate & 3.34384 & 2 & 1.67192 & 477.15 & 0.000 \\
\hline Power fluctuations & 1.98410 & 2 & 0.99205 & 283.12 & 0.000 \\
\hline Models & 0.00629 & 2 & 0.00314 & 0.90 & 0.412 \\
\hline Error & 0.25228 & 72 & 0.00350 & & \\
\hline
\end{tabular}

The battery capacity affects the peak power and the average energy stored in the battery. The charging speed and power fluctuations have a relevant effect on all measures analyzed. Finally, the switch-off (or not switch-off) policies affect mainly the energy consumed over the peak power.

Figure 3 shows the main effect plot of the parameters analyzed that highlights the difference of importance among the parameters. In this figure, NO indicates that no policy has been considered, whereas UP and UPD indicate that the Upstream policy and the Upstream and Downstream policy have been adopted, respectively.

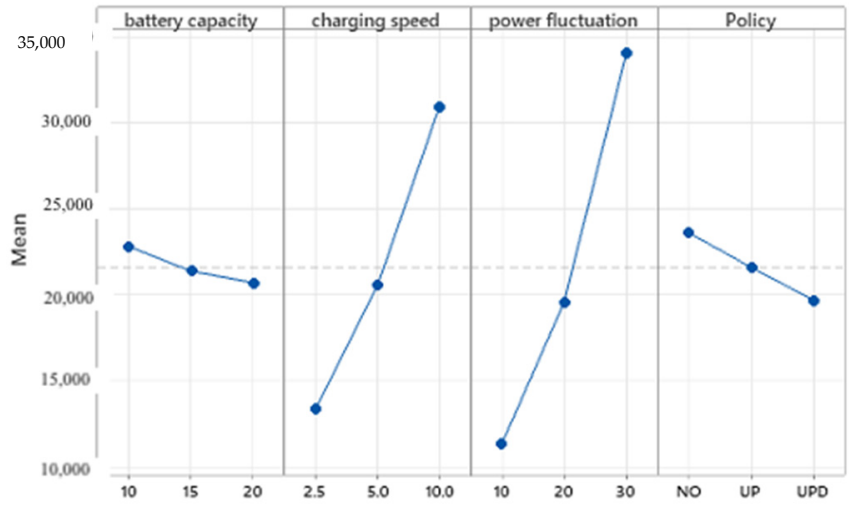

Main effect on Energy over peak power

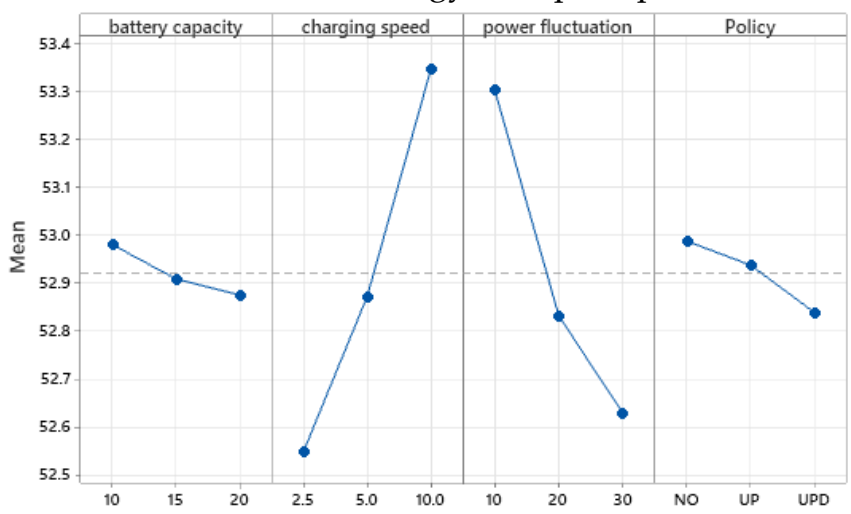

Main effect on Average power utilization

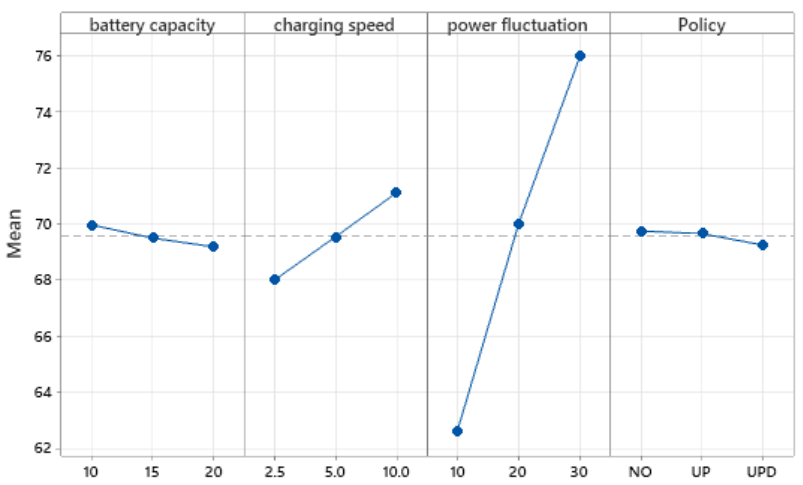

Main effect on Peak power

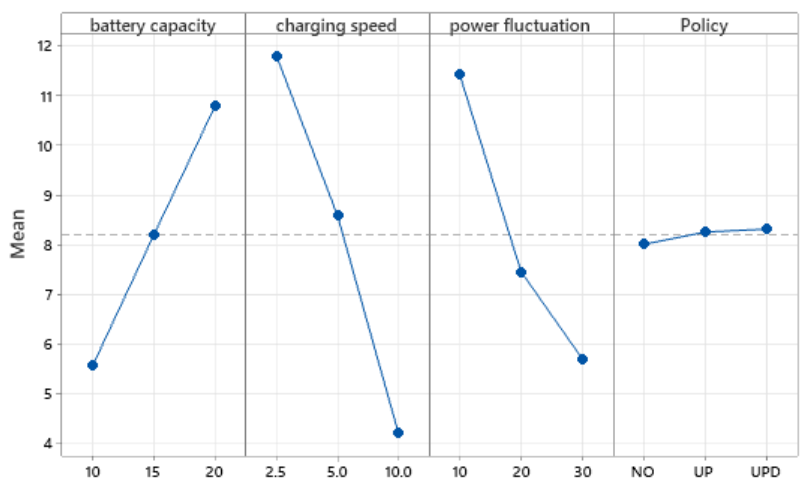

Main effect on Battery level use

Figure 3. Cont. 


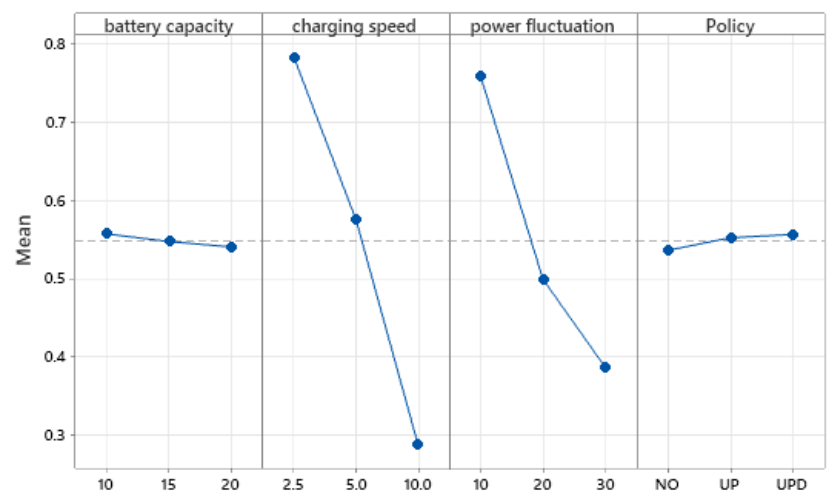

Main effect on Average percentage use of battery capacity

Figure 3. Graphs of the response mean for each factor level.

Figure 4 shows the benefits obtained by the introduction of the battery without a switch-off policy. These figures report the energy used over the power peak constraint compared to the model without battery as a benchmark. For each power variation, the surface reports the reduction of energy over the peak power constraint, changing the battery capacity and charge rate. The benefits are relevant for each experimental class studied. As the reader can notice, the reduction of the energy over the peak power constraint is about $85 \%$ for the higher charge rate for the three power variations. The use of a lower charge rate reduces this energy from $55 \%$ to $25 \%$ from the lower to higher power variation.

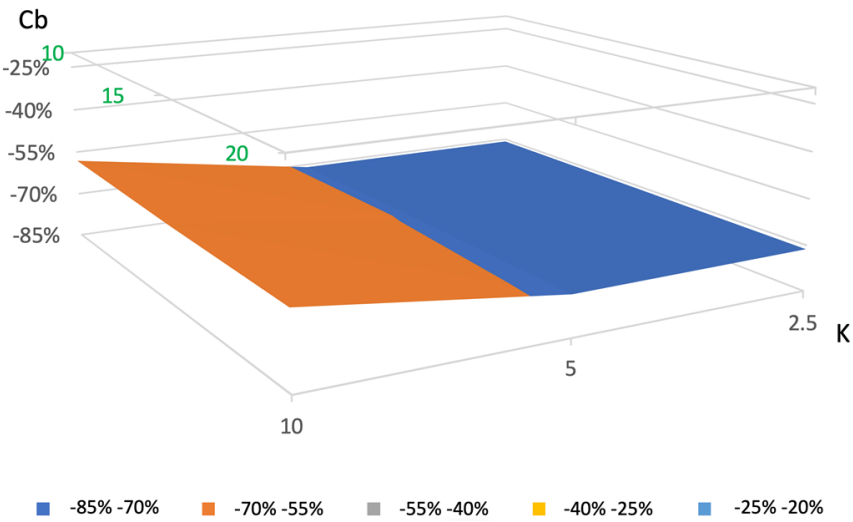

(a) $10 \%$ power variation

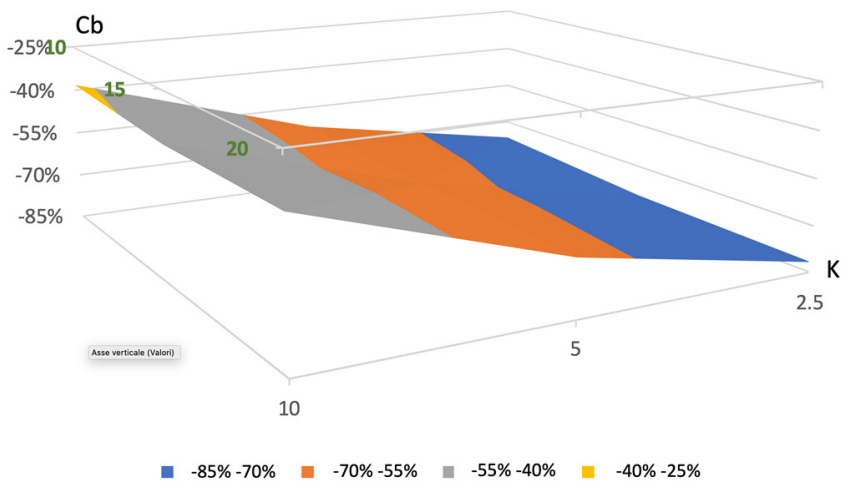

(b) $20 \%$ power variation

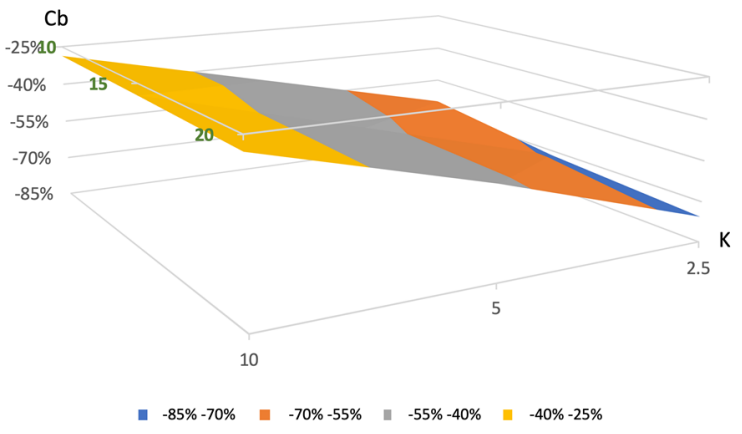

(c) $30 \%$ power variation

Figure 4. Energy over peak power.

The slope of the surface highlights how the charge rate has a relevant impact on the reduction of the energy over the peak power. The slope of the surface over the charge rate is more evident when the variation of the power is higher. The three capacities of the battery 
tested have a minor impact on the energy over the peak power. The above results suggest how it is more important to invest on the charge rate than the capacity of the battery.

Table 3 shows the improvements of the switch-off policies comparing the reduction of the models with switch-off policies with no switch-off using the energy storage system.

Table 3. Energy used over the peak power switch-off policies.

\begin{tabular}{|c|c|c|c|c|c|c|c|}
\hline \multicolumn{5}{|l|}{ Power $10 \%$} & \multicolumn{3}{|c|}{ UP\&D Policy } \\
\hline \multicolumn{5}{|c|}{ Battery capacity $[k W * P T i] \rightarrow$} & \multicolumn{3}{|c|}{ Battery capacity $[k W * P T i] \rightarrow$} \\
\hline $\begin{array}{c}\text { Charging speed } \\
\mathrm{K}\left[k W^{*} P T i / \text { minute }\right] \downarrow\end{array}$ & 10 & 15 & 20 & $\begin{array}{c}\text { Charging speed } \\
K\left[k W^{*} P T i / \text { minute }\right] \downarrow\end{array}$ & 10 & 15 & 20 \\
\hline 10 & $-9.92 \%$ & $-10.25 \%$ & $-10.52 \%$ & 10 & $-16.71 \%$ & $-18.66 \%$ & $-19.00 \%$ \\
\hline 5 & $-8.13 \%$ & $-10.19 \%$ & $-6.93 \%$ & 5 & $-3.79 \%$ & $-3.32 \%$ & $-3.28 \%$ \\
\hline 2.5 & $-10.95 \%$ & $-8.44 \%$ & $-7.71 \%$ & 2.5 & $-5.85 \%$ & $-5.64 \%$ & $-4.50 \%$ \\
\hline Power $20 \%$ & \multicolumn{3}{|c|}{ UP policy } & & \multicolumn{3}{|c|}{ UP\&D policy } \\
\hline \multicolumn{5}{|c|}{ Battery capacity $[k W * P T i] \rightarrow$} & \multicolumn{3}{|c|}{ Battery capacity $[k W * P T i] \rightarrow$} \\
\hline $\begin{array}{c}\text { Charging speed } \\
K\left[k W^{*} P T i / \text { minute }\right] \downarrow\end{array}$ & 10 & 15 & 20 & $\begin{array}{c}\text { Charging speed } \\
\mathrm{K}\left[k W^{*} P T i / \text { minute }\right] \downarrow\end{array}$ & 10 & 15 & 20 \\
\hline 10 & $-6.51 \%$ & $-3.98 \%$ & $-6.53 \%$ & 10 & $-17.97 \%$ & $-14.08 \%$ & $-15.99 \%$ \\
\hline 5 & $-7.03 \%$ & $-8.87 \%$ & $-10.83 \%$ & 5 & $-15.21 \%$ & $-22.58 \%$ & $-25.51 \%$ \\
\hline 2.5 & $-5.98 \%$ & $-1.77 \%$ & $-7.61 \%$ & 2.5 & $-11.54 \%$ & $-8.35 \%$ & $-9.86 \%$ \\
\hline Power 30\% & \multicolumn{3}{|c|}{ UP policy } & & \multicolumn{3}{|c|}{ UP\&D policy } \\
\hline \multicolumn{5}{|c|}{ Battery capacity $[k W * P T i] \rightarrow$} & \multicolumn{3}{|c|}{ Battery capacity $[k W * P T i] \rightarrow$} \\
\hline $\begin{array}{c}\text { Charging speed } \\
K\left[k W^{*} P T i / \text { minute }\right] \downarrow\end{array}$ & 10 & 15 & 20 & $\begin{array}{c}\text { Charging speed } \\
\mathrm{K}\left[k W^{*} P T i / \text { minute }\right] \downarrow\end{array}$ & 10 & 15 & 20 \\
\hline 10 & $-8.91 \%$ & $-8.92 \%$ & $-9.29 \%$ & 10 & $-14.66 \%$ & $-15.41 \%$ & $-13.44 \%$ \\
\hline 5 & $-11.02 \%$ & $-10.85 \%$ & $-8.84 \%$ & 5 & $-20.19 \%$ & $-20.38 \%$ & $-21.67 \%$ \\
\hline 2.5 & $-10.99 \%$ & $-7.97 \%$ & $-6.42 \%$ & 2.5 & $-23.46 \%$ & $-26.70 \%$ & $-28.23 \%$ \\
\hline
\end{tabular}

The negative percentage reported in Table 3 is the reduction of energy used over the peak power constraints. The behavior is very different when the power fluctuation changes. For the case with $10 \%$ of power fluctuation, the UP policy is more robust to the battery capacity and charging speed. The UP\&D policy performs better with a lower charging speed. The UP\&D leads to better performance than the UP policy for medium and high-power fluctuations. The charging speed is relevant for the two policies when the power fluctuation is higher. From these results, it can be drawn that the switch-policy (in particular, UP\&D) can improve this performance with lower characteristics (capacity and charging speed) of the battery.

The above results highlight how the introduction of the switch-off policies can improve the performance of the energy storage system, in particular when the charging speed is not the lower value.

The switch-off policies do not improve significantly the average use of the electricity grid, the improvements are always under 1\% compared with the model with battery and without switch-off policy. Therefore, Table 4 reports the comparison between the introduction of the battery and the no battery model. In Appendix A, Table A1 shows the energy used over the peak power in the models with and without the energy storage. The introduction of the battery allows to load more uniformly the electricity grid, and this is better when the charging speed reduces and power fluctuations increase. The battery capacity has a lower impact on this performance.

Table 5 shows the average utilization of the battery capacity. The battery capacity is computed as the ratio between the average use to the capacity. The cases with higher and lower utilization of the battery are highlighted with gray background. The cases highlighted are characterized by a specific combination of charge rate and power fluctuations. 
Table 4. Average use of electricity grid.

\begin{tabular}{|c|c|c|c|}
\hline \multicolumn{4}{|c|}{ Battery vs. No Battery } \\
\hline \multicolumn{4}{|l|}{ Power $10 \%$} \\
\hline & \multicolumn{3}{|c|}{ Battery capacity $\left[k W^{*} P T i\right] \rightarrow$} \\
\hline $\begin{array}{l}\text { Charging speed } K \\
{\left[k W^{*} P T i / \text { minute }\right] \downarrow}\end{array}$ & 10 & 15 & 20 \\
\hline 10 & $-1.59 \%$ & $-1.68 \%$ & $-1.70 \%$ \\
\hline 5 & $-1.99 \%$ & $-1.99 \%$ & $-2.01 \%$ \\
\hline 2.5 & $-2.01 \%$ & $-2.02 \%$ & $-2.03 \%$ \\
\hline \multicolumn{4}{|l|}{ Power $20 \%$} \\
\hline & \multicolumn{3}{|c|}{ Battery capacity $\left[k W^{*} P T i\right] \rightarrow$} \\
\hline $\begin{array}{l}\text { Charging speed } K \\
{\left[k W^{*} P T i / \text { minute }\right] \downarrow}\end{array}$ & 10 & 15 & 20 \\
\hline 10 & $-1.74 \%$ & $-1.82 \%$ & $-1.84 \%$ \\
\hline 5 & $-2.71 \%$ & $-2.88 \%$ & $-2.97 \%$ \\
\hline 2.5 & $-3.35 \%$ & $-3.55 \%$ & $-3.62 \%$ \\
\hline \multicolumn{4}{|l|}{ Power $30 \%$} \\
\hline & \multicolumn{3}{|c|}{ Battery capacity $\left[k W^{*} P T i\right] \rightarrow$} \\
\hline $\begin{array}{l}\text { Charging speed } K \\
{\left[k W^{*} P T i / \text { minute }\right] \downarrow}\end{array}$ & 10 & 15 & 20 \\
\hline 10 & $-1.79 \%$ & $-1.86 \%$ & $-1.90 \%$ \\
\hline 5 & $-2.92 \%$ & $-3.08 \%$ & $-3.19 \%$ \\
\hline 2.5 & $-3.99 \%$ & $-4.40 \%$ & $-4.62 \%$ \\
\hline
\end{tabular}

Table 5. Average utilization of the battery capacity.

\begin{tabular}{cccccc}
\hline Exp. No. & \% Battery & Exp. No. & \% Battery & Exp. No. & \% Battery \\
\hline 1 & $44.53 \%$ & 28 & $46.99 \%$ & 55 & $50.56 \%$ \\
2 & $42.42 \%$ & 29 & $45.55 \%$ & 56 & $48.49 \%$ \\
3 & $41.29 \%$ & 30 & $44.73 \%$ & 57 & $46.56 \%$ \\
4 & $82.01 \%$ & 31 & $83.36 \%$ & 58 & $86.17 \%$ \\
5 & $86.50 \%$ & 32 & $87.74 \%$ & 59 & $90.33 \%$ \\
6 & $88.49 \%$ & 33 & $89.43 \%$ & 60 & $91.78 \%$ \\
7 & $92.94 \%$ & 34 & $93.47 \%$ & 61 & $93.73 \%$ \\
8 & $95.23 \%$ & 35 & $95.59 \%$ & 62 & $95.78 \%$ \\
9 & $95.93 \%$ & 36 & $96.15 \%$ & 63 & $96.38 \%$ \\
10 & $26.36 \%$ & 37 & $28.09 \%$ & 64 & $24.46 \%$ \\
11 & $22.26 \%$ & 38 & $24.09 \%$ & 65 & $18.58 \%$ \\
12 & $19.84 \%$ & 39 & $21.63 \%$ & 66 & $15.36 \%$ \\
13 & $49.47 \%$ & 40 & $51.26 \%$ & 67 & $53.91 \%$ \\
14 & $46.36 \%$ & 41 & $48.62 \%$ & 68 & $52.25 \%$ \\
15 & $44.37 \%$ & 42 & $46.92 \%$ & 69 & $50.94 \%$ \\
16 & $73.18 \%$ & 43 & $74.29 \%$ & 70 & $76.21 \%$ \\
17 & $76.72 \%$ & 44 & $78.00 \%$ & 71 & $80.83 \%$ \\
18 & $79.46 \%$ & 45 & $80.66 \%$ & 72 & $83.97 \%$ \\
19 & $22.52 \%$ & 46 & $24.13 \%$ & 73 & $20.09 \%$ \\
20 & $18.19 \%$ & 47 & $19.81 \%$ & 74 & $14.71 \%$ \\
21 & $15.70 \%$ & 48 & $17.17 \%$ & 75 & $11.90 \%$ \\
22 & $39.63 \%$ & 49 & $41.23 \%$ & 76 & $41.35 \%$ \\
23 & $34.32 \%$ & 50 & $36.22 \%$ & 77 & $35.38 \%$ \\
24 & $31.13 \%$ & 51 & $33.08 \%$ & 78 & $31.02 \%$ \\
25 & $60.34 \%$ & 52 & $61.56 \%$ & 79 & $63.15 \%$ \\
26 & $59.51 \%$ & 53 & $61.01 \%$ & 80 & $64.00 \%$ \\
27 & $59.37 \%$ & 54 & $61.05 \%$ & 81 & $65.41 \%$ \\
\hline
\end{tabular}

The capacity of the battery does not influence the average utilization.

The combination of lower power fluctuation and higher charge rate leads to utilization over $90 \%$, whereas the higher power fluctuation and lower charge rate cause a utilization 
under $20 \%$. These results are important for the choice of charge rate because it determines the price of the battery and deterioration.

From the above results, the following issues can be drawn:

- $\quad$ The introduction of the battery reduces drastically the energy used over the peak power; moreover, the introduction of the battery leads to a more uniform load of the electricity grid.

- The switch-off policy allows to further reduce this part of energy. The introduction of the switch allows to improve this performance with lower battery performance and therefore with lower costs. The UP\&D policy performs better when the power fluctuation is higher. The switch-off policy improves the performance when the charging speed is slow.

- The charge rate and power fluctuation are the more important factors; moreover, these factors are relevant for the average utilization of the battery. Therefore, the definition of these parameters can affect the deterioration of the battery over the medium horizon.

\section{Conclusions and Future Development}

The research proposed in this paper extends the use of energy storage systems integrated with switch-off policies to reduce the energy costs in manufacturing systems. In response, our first research question asked: what is the impact of the energy storage system characteristics to reduce the energy use over the peak power constraint? The simulation results have demonstrated how the major impact is due to the charge rate and power fluctuations of the tasks, whereas the battery capacity and the particular models with energy storage systems have a lower impact.

However, in response to our second research question: Can the switch-off policies significantly improve the use of the energy storage system to reduce the energy use over the peak power constraint? The switch-off policies can improve further the energy costs reduction. In particular, the switch-off policies have a greater impact when the speed of charging is lower. This means that the introduction of switch-off policies allows using batteries at lower costs because the charge rate can be lower. The results of the model proposed can support, at the managerial level, the choice of the combination of battery characteristics (charging speed and capacity) related to the power fluctuation of the manufacturing tasks to reduce the peak power penalty.

Future development paths can be the following: the investment cost analysis of the battery related to the characteristics (capacity, charging speed, etc.) should be studied to evaluate the energy-saving costs globally. Also, the degradation of battery and thus the performance losses, the economic and technical benefits of energy storage replacement will be analyzed. The comparison of different battery technologies and their performances will be the focus of future work.

Author Contributions: Conceptualization, P.R. and S.M.; P.R. designed and performed the experiments; P.R. and S.M. wrote and revised the paper. All authors have read and agreed to the published version of the manuscript.

Funding: This research received no external funding.

Institutional Review Board Statement: Not applicable.

Informed Consent Statement: Not applicable.

Data Availability Statement: Not applicable.

Acknowledgments: We would like to thank the anonymous reviewers for their careful reading of our manuscript and their many insightful comments and suggestions.

Conflicts of Interest: The authors declare no conflict of interest. 


\section{Appendix A}

Table A1. Energy used over the peak power.

\begin{tabular}{|c|c|c|c|}
\hline \multicolumn{4}{|c|}{ Battery vs. No Battery } \\
\hline & \multirow{2}{*}{\multicolumn{3}{|c|}{ Battery capacity $\rightarrow$}} \\
\hline & & & \\
\hline Charging speed $\downarrow$ & 10 & 15 & 20 \\
\hline 10 & $-58.14 \%$ & $-59.94 \%$ & $-60.91 \%$ \\
\hline 5 & $-71.02 \%$ & $-71.02 \%$ & $-71.74 \%$ \\
\hline 2.5 & $-70.92 \%$ & $-71.04 \%$ & $-71.29 \%$ \\
\hline \multicolumn{4}{|l|}{ Power $20 \%$} \\
\hline & \multicolumn{3}{|c|}{ Battery capacity $\rightarrow$} \\
\hline Charging speed $\downarrow$ & 10 & 15 & 20 \\
\hline 10 & $-38.19 \%$ & $-41.58 \%$ & $-40.99 \%$ \\
\hline 5 & $-62.41 \%$ & $-64.81 \%$ & $-66.53 \%$ \\
\hline 2.5 & $-76.49 \%$ & $-80.58 \%$ & $-81.70 \%$ \\
\hline \multicolumn{4}{|l|}{ Power $30 \%$} \\
\hline & \multicolumn{3}{|c|}{ Battery capacity $\rightarrow$} \\
\hline Charging speed $\downarrow$ & 10 & 15 & 20 \\
\hline 10 & $-28.67 \%$ & $-29.27 \%$ & $-30.07 \%$ \\
\hline 5 & $-46.79 \%$ & $-50.45 \%$ & $-51.41 \%$ \\
\hline 2.5 & $-65.03 \%$ & $-71.86 \%$ & $-75.63 \%$ \\
\hline
\end{tabular}

Table A2. Main data used for the simulation analysis.

\begin{tabular}{|c|c|c|c|c|c|c|c|c|}
\hline Exp. No. & $\begin{array}{c}\text { Battery } \\
\text { Capacity }\end{array}$ & $\begin{array}{c}\text { Charge } \\
\text { Rate }\end{array}$ & $\begin{array}{c}\text { Power } \\
\text { Variability }\end{array}$ & $\begin{array}{l}\text { Switch-Off } \\
\text { Policy }\end{array}$ & $\begin{array}{c}\text { Energy } \\
\text { Over Peak }\end{array}$ & $\begin{array}{c}\text { Average Grid } \\
\text { Utilization }\end{array}$ & $\begin{array}{c}\text { Peak Grid } \\
\text { Power }\end{array}$ & $\begin{array}{c}\text { Battery } \\
\text { Utilization }\end{array}$ \\
\hline 1 & 10 & 10 & 10 & $\mathrm{NO}$ & $15,487.78$ & 53.52 & 65.48 & 4.45 \\
\hline 2 & 15 & 10 & 10 & $\mathrm{NO}$ & $14,821.92$ & 53.47 & 65.44 & 6.36 \\
\hline 3 & 20 & 10 & 10 & $\mathrm{NO}$ & $14,464.80$ & 53.46 & 65.41 & 8.26 \\
\hline 4 & 10 & 5 & 10 & $\mathrm{NO}$ & $10,724.26$ & 53.30 & 64.10 & 8.20 \\
\hline 5 & 15 & 5 & 10 & $\mathrm{NO}$ & $10,721.66$ & 53.30 & 62.72 & 12.97 \\
\hline 6 & 20 & 5 & 10 & $\mathrm{NO}$ & $10,457.28$ & 53.29 & 61.14 & 17.70 \\
\hline 7 & 10 & 2.5 & 10 & $\mathrm{NO}$ & $10,759.10$ & 53.29 & 61.46 & 9.29 \\
\hline 8 & 15 & 2.5 & 10 & $\mathrm{NO}$ & $10,714.18$ & 53.28 & 60.04 & 14.29 \\
\hline 9 & 20 & 2.5 & 10 & NO & $10,620.86$ & 53.28 & 60.00 & 19.19 \\
\hline 10 & 10 & 10 & 20 & $\mathrm{NO}$ & $34,001.28$ & 53.43 & 71.23 & 2.64 \\
\hline 11 & 15 & 10 & 20 & $\mathrm{NO}$ & $32,135.33$ & 53.39 & 71.22 & 3.34 \\
\hline 12 & 20 & 10 & 20 & $\mathrm{NO}$ & $32,462.21$ & 53.38 & 71.21 & 3.97 \\
\hline 13 & 10 & 5 & 20 & $\mathrm{NO}$ & $20,674.94$ & 52.91 & 70.59 & 4.95 \\
\hline 14 & 15 & 5 & 20 & $\mathrm{NO}$ & $19,357.92$ & 52.81 & 70.50 & 6.95 \\
\hline 15 & 20 & 5 & 20 & $\mathrm{NO}$ & $18,412.70$ & 52.76 & 70.45 & 8.87 \\
\hline 16 & 10 & 2.5 & 20 & $\mathrm{NO}$ & $12,932.35$ & 52.55 & 69.68 & 7.32 \\
\hline 17 & 15 & 2.5 & 20 & $\mathrm{NO}$ & $10,684.22$ & 52.45 & 69.02 & 11.51 \\
\hline 18 & 20 & 2.5 & 20 & $\mathrm{NO}$ & $10,064.74$ & 52.41 & 68.29 & 15.89 \\
\hline 19 & 10 & 10 & 30 & $\mathrm{NO}$ & $53,500.03$ & 53.41 & 76.92 & 2.25 \\
\hline 20 & 15 & 10 & 30 & $\mathrm{NO}$ & $53,051.90$ & 53.38 & 76.92 & 2.73 \\
\hline 21 & 20 & 10 & 30 & $\mathrm{NO}$ & $52,449.98$ & 53.35 & 76.92 & 3.14 \\
\hline
\end{tabular}


Table A2. Cont.

\begin{tabular}{|c|c|c|c|c|c|c|c|c|}
\hline Exp. No. & $\begin{array}{l}\text { Battery } \\
\text { Capacity }\end{array}$ & $\begin{array}{l}\text { Charge } \\
\text { Rate }\end{array}$ & $\begin{array}{c}\text { Power } \\
\text { Variability }\end{array}$ & $\begin{array}{c}\text { Switch-Off } \\
\text { Policy }\end{array}$ & $\begin{array}{c}\text { Energy } \\
\text { Over Peak }\end{array}$ & $\begin{array}{c}\text { Average Grid } \\
\text { Utilization }\end{array}$ & $\begin{array}{c}\text { Peak Grid } \\
\text { Power }\end{array}$ & $\begin{array}{c}\text { Battery } \\
\text { Utilization }\end{array}$ \\
\hline 22 & 10 & 5 & 30 & $\mathrm{NO}$ & $39,907.87$ & 52.80 & 76.30 & 3.96 \\
\hline 23 & 15 & 5 & 30 & $\mathrm{NO}$ & $37,167.26$ & 52.71 & 76.26 & 5.15 \\
\hline 24 & 20 & 5 & 30 & $\mathrm{NO}$ & $36,446.69$ & 52.65 & 76.24 & 6.23 \\
\hline 25 & 10 & 2.5 & 30 & NO & $26,228.45$ & 52.22 & 75.55 & 6.03 \\
\hline 26 & 15 & 2.5 & 30 & $\mathrm{NO}$ & $21,108.67$ & 52.00 & 75.30 & 8.93 \\
\hline 27 & 20 & 2.5 & 30 & NO & $18,281.66$ & 51.88 & 75.08 & 11.87 \\
\hline 28 & 10 & 10 & 10 & UP & $13,950.72$ & 53.45 & 65.47 & 4.70 \\
\hline 29 & 15 & 10 & 10 & UP & $13,303.30$ & 53.41 & 65.41 & 6.83 \\
\hline 30 & 20 & 10 & 10 & UP & $12,942.72$ & 53.38 & 65.39 & 8.95 \\
\hline 31 & 10 & 5 & 10 & UP & 9851.90 & 53.26 & 63.94 & 8.34 \\
\hline 32 & 15 & 5 & 10 & UP & 9628.99 & 53.25 & 62.40 & 13.16 \\
\hline 33 & 20 & 5 & 10 & UP & 9732.96 & 53.26 & 60.87 & 17.89 \\
\hline 34 & 10 & 2.5 & 10 & UP & 9581.47 & 53.25 & 61.23 & 9.35 \\
\hline 35 & 15 & 2.5 & 10 & UP & 9809.57 & 53.25 & 60.04 & 14.34 \\
\hline 36 & 20 & 2.5 & 10 & UP & 9802.08 & 53.25 & 60.00 & 19.23 \\
\hline 37 & 10 & 10 & 20 & UP & $31,786.85$ & 53.37 & 71.22 & 2.81 \\
\hline 38 & 15 & 10 & 20 & UP & $30,857.18$ & 53.33 & 71.21 & 3.61 \\
\hline 39 & 20 & 10 & 20 & UP & $30,343.68$ & 53.30 & 71.21 & 4.33 \\
\hline 40 & 10 & 5 & 20 & UP & $19,221.98$ & 52.85 & 70.51 & 5.13 \\
\hline 41 & 15 & 5 & 20 & UP & $17,640.29$ & 52.76 & 70.43 & 7.29 \\
\hline 42 & 20 & 5 & 20 & UP & $16,418.88$ & 52.71 & 70.36 & 9.38 \\
\hline 43 & 10 & 2.5 & 20 & UP & $12,159.36$ & 52.52 & 69.54 & 7.43 \\
\hline 44 & 15 & 2.5 & 20 & UP & $10,495.01$ & 52.41 & 68.82 & 11.70 \\
\hline 45 & 20 & 2.5 & 20 & UP & 9298.66 & 52.39 & 68.03 & 16.13 \\
\hline 46 & 10 & 10 & 30 & UP & $48,734.21$ & 53.35 & 76.91 & 2.41 \\
\hline 47 & 15 & 10 & 30 & UP & $48,320.06$ & 53.30 & 76.90 & 2.97 \\
\hline 48 & 20 & 10 & 30 & UP & $47,577.31$ & 53.28 & 76.90 & 3.43 \\
\hline 49 & 10 & 5 & 30 & UP & $35,508.38$ & 52.75 & 76.23 & 4.12 \\
\hline 50 & 15 & 5 & 30 & UP & $33,134.69$ & 52.64 & 76.19 & 5.43 \\
\hline 51 & 20 & 5 & 30 & UP & $33,224.26$ & 52.59 & 76.16 & 6.62 \\
\hline 52 & 10 & 2.5 & 30 & UP & $23,346.43$ & 52.19 & 75.44 & 6.16 \\
\hline 53 & 15 & 2.5 & 30 & UP & $19,425.60$ & 51.97 & 75.18 & 9.15 \\
\hline 54 & 20 & 2.5 & 30 & UP & $17,107.20$ & 51.85 & 74.94 & 12.21 \\
\hline 55 & 10 & 10 & 10 & UPD & $12,900.10$ & 53.34 & 65.20 & 5.06 \\
\hline 56 & 15 & 10 & 10 & UPD & $12,056.26$ & 53.31 & 65.12 & 7.27 \\
\hline 57 & 20 & 10 & 10 & UPD & $11,716.13$ & 53.29 & 65.07 & 9.31 \\
\hline 58 & 10 & 5 & 10 & UPD & $10,317.89$ & 53.22 & 63.22 & 8.62 \\
\hline 59 & 15 & 5 & 10 & UPD & $10,365.98$ & 53.22 & 60.94 & 13.55 \\
\hline 60 & 20 & 5 & 10 & UPD & $10,113.98$ & 53.22 & 60.12 & 18.36 \\
\hline 61 & 10 & 2.5 & 10 & UPD & $10,129.82$ & 53.21 & 60.72 & 9.37 \\
\hline 62 & 15 & 2.5 & 10 & UPD & $10,110.24$ & 53.22 & 60.01 & 14.37 \\
\hline
\end{tabular}


Table A2. Cont.

\begin{tabular}{|c|c|c|c|c|c|c|c|c|}
\hline Exp. No. & $\begin{array}{c}\text { Battery } \\
\text { Capacity }\end{array}$ & $\begin{array}{c}\text { Charge } \\
\text { Rate }\end{array}$ & $\begin{array}{c}\text { Power } \\
\text { Variability }\end{array}$ & $\begin{array}{c}\text { Switch-Off } \\
\text { Policy }\end{array}$ & $\begin{array}{c}\text { Energy } \\
\text { Over Peak }\end{array}$ & $\begin{array}{l}\text { Average Grid } \\
\text { Utilization }\end{array}$ & $\begin{array}{l}\text { Peak Grid } \\
\text { Power }\end{array}$ & $\begin{array}{c}\text { Battery } \\
\text { Utilization }\end{array}$ \\
\hline 63 & 20 & 2.5 & 10 & UPD & $10,143.07$ & 53.21 & 60.00 & 19.28 \\
\hline 64 & 10 & 10 & 20 & UPD & $27,890.50$ & 53.26 & 71.09 & 2.45 \\
\hline 65 & 15 & 10 & 20 & UPD & $27,611.42$ & 53.23 & 71.08 & 2.79 \\
\hline 66 & 20 & 10 & 20 & UPD & $27,270.72$ & 53.23 & 71.07 & 3.07 \\
\hline 67 & 10 & 5 & 20 & UPD & $17,529.41$ & 52.69 & 70.27 & 5.39 \\
\hline 68 & 15 & 5 & 20 & UPD & $14,987.81$ & 52.60 & 70.09 & 7.84 \\
\hline 69 & 20 & 5 & 20 & UPD & $13,716.29$ & 52.55 & 69.95 & 10.19 \\
\hline 70 & 10 & 2.5 & 20 & UPD & $11,439.36$ & 52.45 & 69.15 & 7.62 \\
\hline 71 & 15 & 2.5 & 20 & UPD & 9792.29 & 52.36 & 68.05 & 12.12 \\
\hline 72 & 20 & 2.5 & 20 & UPD & 9072.58 & 52.35 & 66.59 & 16.79 \\
\hline 73 & 10 & 10 & 30 & UPD & $45,658.08$ & 53.24 & 76.74 & 2.01 \\
\hline 74 & 15 & 10 & 30 & UPD & $44,876.16$ & 53.23 & 76.74 & 2.21 \\
\hline 75 & 20 & 10 & 30 & UPD & $45,399.17$ & 53.22 & 76.73 & 2.38 \\
\hline 76 & 10 & 5 & 30 & UPD & $31,851.36$ & 52.57 & 76.02 & 4.14 \\
\hline 77 & 15 & 5 & 30 & UPD & $29,591.14$ & 52.45 & 75.94 & 5.31 \\
\hline 78 & 20 & 5 & 30 & UPD & $28,547.42$ & 52.40 & 75.90 & 6.20 \\
\hline 79 & 10 & 2.5 & 30 & UPD & $20,074.46$ & 52.06 & 75.14 & 6.32 \\
\hline 80 & 15 & 2.5 & 30 & UPD & $15,473.66$ & 51.82 & 74.70 & 9.60 \\
\hline 81 & 20 & 2.5 & 30 & UPD & $13,120.13$ & 51.70 & 74.25 & 13.08 \\
\hline
\end{tabular}

\section{References}

1. Ritchie, H.; Roser, M. $\mathrm{CO}_{2}$ and Greenhouse Gas Emissions. Our World in Data. 2020. Available online: https://ourworldindata. org/co2-and-other-greenhouse-gas-emissions (accessed on 24 January 2022).

2. IRENA. Reaching Zero with Renewables: Eliminating CO2 Emissions from Industry and Transport in Line with the 1.50C Climate Goal. Abu Dhabi, 2020. Available online: https:/ /www.irena.org/publications/2020/Sep/Reaching-Zero-with-Renewables (accessed on 24 January 2022).

3. Gutowski, T.; Dahmus, J.; Thiriez, A. Electrical energy requirements for manufacturing processes. In Proceedings of the 13th CIRP International Conference on Life Cycle Engineering, Leuven, Belgium, 31 May-2 June 2006; pp. $623-628$.

4. Chen, C.-Y.; Liao, C.-J. A linear programming approach to the electricity contract capacity problem. Appl. Math. Model. 2011, 35, 4077-4082. [CrossRef]

5. McLaren, J.; Gagnon, P.; Zimny-Schmitt, D.; DeMinco, M.; Wilson, E. Maximum Demand Charge Rates for Commercial and Industrial Electricity Tariffs in the United States; National Renewable Energy Laboratory, 2017. Available online: https://data.nrel.gov/ submissions/74 (accessed on 6 January 2022).

6. Zubi, G.; Dufo-López, R.; Carvalho, M.; Pasaoglu, G. The lithium-ion battery: State of the art and future perspectives. Renew. Sustain. Energy Rev. 2018, 89, 292-308. [CrossRef]

7. Ahmadi, L.; Young, S.B.; Fowler, M.; Fraser, R.A.; Achachlouei, M.A. A cascaded life cycle: Reuse of electric vehicle lithium-ion battery packs in energy storage systems. Int. J. Life Cycle Assess. 2017, 22, 111-124. [CrossRef]

8. Costa, C.M.; Barbosa, J.C.; Gonçalves, R.; Castro, H.; Campo, F.J.D.; Lanceros-Méndez, S. Recycling and environmental issues of lithium-ion batteries: Advances, challenges and opportunities. Energy Storage Mater. 2021, 37, 433-465. [CrossRef]

9. Renna, P.; Materi, S. A Literature Review of Energy Efficiency and Sustainability in Manufacturing Systems. Appl. Sci. 2021, 11, 7366. [CrossRef]

10. Islam, M.M.; Nagrial, M.; Rizk, J.; Hellany, A. Dual stage microgrid energy resource optimization strategy considering renewable and battery storage systems. Int. J. Energy Res. 2021, 45, 21340-21364. [CrossRef]

11. Mohammadi-Ivatloo, B.; Jabari, F. Operation, Planning, and Analysis of Energy Storage Systems in Smart Energy Hubs; Springer: Cham, Switzerland, 2018. [CrossRef]

12. Materi, S.; D'Angola, A.; Enescu, D.; Renna, P. Reducing energy costs and $\mathrm{CO}_{2}$ emissions by production system energy flexibility through the integration of renewable energy. Prod. Eng. 2021, 15, 667-681. [CrossRef] 
13. Fernandez, M.; Li, L.; Sun, Z. "Just-for-Peak" buffer inventory for peak electricity demand reduction of manufacturing systems. Int. J. Prod. Econ. 2013, 146, 178-184. [CrossRef]

14. Fang, K.; Uhan, N.A.; Zhao, F.; Sutherland, J.W. Flow shop scheduling with peak power consumption constraints. Ann. Oper. Res. 2013, 206, 115-145. [CrossRef]

15. Liu, C.-H.; Nanthapodej, R.; Hsu, S.-Y. Scheduling two interfering job sets on parallel machines under peak power constraint. Prod. Eng. 2018, 12, 611-619. [CrossRef]

16. Wang, J.; Wang, L. Decoding methods for the flow shop scheduling with peak power consumption constraints. Int. J. Prod. Res. 2019, 57, 3200-3218. [CrossRef]

17. Sun, Z.; Li, L.; Fernandez, M.; Wang, J. Inventory control for peak electricity demand reduction of manufacturing systems considering the tradeoff between production loss and energy savings. J. Clean. Prod. 2014, 82, 84-93. [CrossRef]

18. Frigerio, N.; Matta, A. Energy Efficient Control Strategy for Machine Tools with Stochastic Arrivals and Time Dependent Warm-up. Procedia CIRP 2014, 15, 56-61. [CrossRef]

19. Frigerio, N.; Matta, A. Energy-Efficient Control Strategies for Machine Tools With Stochastic Arrivals. IEEE Trans. Autom. Sci. Eng. 2015, 12, 50-61. [CrossRef]

20. Su, H.; Frigerio, N.; Matta, A. Energy Saving Opportunities and Value of Information: A Trade-off in a Production Line. Procedia CIRP 2016, 48, 301-306. [CrossRef]

21. Jia, Z.; Zhang, L.; Arinez, J.; Xiao, G. Performance analysis of Bernoulli serial production lines with switch-on/off machine control. In Proceedings of the 2015 IEEE International Conference on Automation Science and Engineering (CASE), Gothenburg, Sweden, 24-28 August 2015; IEEE: Gothenburg, Sweden, 2015; pp. 477-482. [CrossRef]

22. Jia, Z.; Zhang, L.; Arinez, J.; Xiao, G. Performance analysis for serial production lines with Bernoulli Machines and Real-time WIP-based Machine switch-on/off control. Int. J. Prod. Res. 2016, 54, 6285-6301. [CrossRef]

23. Fei, Z.; Li, S.; Chang, Q.; Wang, J.; Huang, Y. Fuzzy Petri Net Based Intelligent Machine Operation of Energy Efficient Manufacturing System. In Proceedings of the 2018 IEEE 14th International Conference on Automation Science and Engineering (CASE), Munich, Germany, 20-24 August 2018; pp. 1593-1598. [CrossRef]

24. Wang, J.; Xue, J.; Duque, E.T.; Li, S.; Chang, Q. Fuzzy decision of machine switch on-off for energy efficient operation of manufacturing system. In Proceedings of the 2017 13th IEEE Conference on Automation Science and Engineering (CASE), Xi'an, China, 20-23 August 2017; pp. 1158-1162. [CrossRef]

25. Wang, J.; Fei, Z.; Chang, Q.; Fu, Y.; Li, S. Energy-Saving Operation of Multistage Stochastic Manufacturing Systems Based on Fuzzy Logic. Int. J. Simul. Model. 2019, 18, 138-149. [CrossRef]

26. Wang, J.; Fei, Z.; Chang, Q.; Li, S.; Fu, Y. Multi-state decision of unreliable machines for energy-efficient production considering work-in-process inventory. Int. J. Adv. Manuf. Technol. 2019, 102, 1009-1021. [CrossRef]

27. Duque, E.T.; Fei, Z.; Wang, J.; Li, S.; Li, Y.F. Energy Consumption Control of One Machine Manufacturing System with Stochastic Arrivals Based on Fuzzy Logic. In Proceedings of the 2018 IEEE International Conference on Industrial Engineering and Engineering Management (IEEM), Bangkok, Thailand, 16-19 December 2018; pp. 1503-1507. [CrossRef]

28. Marzano, L.; Frigerio, N.; Matta, A. Energy Efficient State Control of Machine Tools: A Time-Based Dynamic Control Policy. In Proceedings of the 2019 IEEE 15th International Conference on Automation Science and Engineering (CASE), Vancouver, BC, Canada, 22-26 August 2019; pp. 596-601. [CrossRef]

29. Renna, P. Energy saving by switch-off policy in a pull-controlled production line. Sustain. Prod. Consum. 2018, 16, 25-32. [CrossRef]

30. Sun, Z.; Li, L. Opportunity Estimation for Real-Time Energy Control of Sustainable Manufacturing Systems. IEEE Trans. Autom. Sci. Eng. 2013, 10, 38-44. [CrossRef]

31. Renna, P.; Materi, S. Switch off policies in job-shop manufacturing systems including workload evaluation. Int. J. Manag. Sci. Eng. Manag. 2021, 16, 254-263. [CrossRef]

32. Schulze, C.; Blume, S.; Siemon, L.; Herrmann, C.; Thiede, S. Towards energy flexible and energy self-sufficient manufacturing systems. Procedia CIRP 2019, 81, 683-688. [CrossRef]

33. Frigerio, N.; Matta, A. Analysis of an Energy Oriented Switching Control of Production Lines. Procedia CIRP 2015, 29, 34-39. [CrossRef]

34. Frigerio, N.; Matta, A. Analysis on Energy Efficient Switching of Machine Tool With Stochastic Arrivals and Buffer Information. IEEE Trans. Autom. Sci. Eng. 2016, 13, 238-246. [CrossRef] 